the platelet counts weekly and the knowledge that a cyclical variation may occur are important in assessing the severity of the thrombocytopenia, the response to treatment, and the timing of surgical procedures.

The documented case in which a patient with clinical thyrotoxicosis and cyclic thrombocytopenia was found to have platelet, thyroid, and mitochondrial antibodies-the latter thought to be suggestive of primary biliary cirrhosis (Doniach et al., 1966) - and a positive antinuclear test (speckled variety) with clinical response to steroids, lends support to the concept that thrombocytopenia may be attributed to disorders of the immunological system.

We are grateful to Dr. N. E. G. Richardson and Dr. A. Woods for their help and advice in the preparation of this case report. The immunological studies were kindly performed by Dr. D.
Doniach at the Middlesex Hospital and Dr. K. L. G. Goldsmith at the Lister Institute.

O. BREY, M.B., B.S.

E. P. R. GARNER, F.I.M.L.T.

D. Wells, M.B., B.S.

Departments of Haematology and Medicine, Epsom District Hospital, Surrey.

REFERENCES

De Gruchy, G. C. (1964). Clinical Haematology in Medical Practice. Oxford, Blackwell Scientific Publications.

Demmer, T. (1921). Folia Haematologica, 22, 74.

Doniach, D., Roitt, I. M., Walker, J. G., and Sherlock, S. (1966). Clinical and Experimental Immunology, 1, 237.

Evans, R. S., Takahashi, K., Duane, R. T., Payne, R., and Liu, C. K. (1951). 'Archives of Internal Medicine, 87, 48.

Genell, S. (1936). Fournal of Obstetrics and Gynaecology of the British Empire, 43,1124.

Pohle, F. J. (1939). American fournal of the Medical Sciences, 197, 40. Skoog, W. A., Lawrence, J. S., and Adams, W. S. (1957). Blood, 12, 844.

\section{Fatal Intestinal Atony in Myxoedema}

\author{
British Medical fournal, 1969, 3, 398
}

Constipation and abdominal distension are well-recognized features of hypothyroidism, but serious atony of the gastrointestinal tract and urinary bladder may result in retention or incontinence of faeces or urine and even in death from intestinal obstruction without external features of hypothyroidism being obvious.

\section{CAse Report}

In 1958 a man aged 59 complained of sore tongue, tiredness, dyspnoea on exertion, paraesthesiae, and intermittent constipation and diarrhoea. He had a normoblastic macrocytic anaemia (haemoglobin $13 \mathrm{~g} . / 100 \mathrm{ml}$.) with histamine-fast achlorhydria. $X$-ray examination showed normal stomach, small intestine, and colon. The vitamin- $B_{12}$ therapy that he was already receiving was continued. In 1960 the macrocytic anaemia was still present. In 1964 he again complained of intermittent constipation and diarrhoea. A barium enema showed a voluminous colon requiring three times the normal quantity of barium.

In January 1967 he was readmitted with persistent bouts of constipation and diarrhoea with distension. For the first time there were external features of hypothyroidism. His skin was coarse and dry, his speech was slow and hoarse, and his movements were lethargic. Psychomotor retardation and delayed tendon jerks were present. The thyroid was not enlarged. Pubic and axillary hair were present. The abdomen was distended and tympanitic. Ascites could not be detected. The pulse was 80 and the heart slightly enlarged. The electrocardiogram showed no features of hypothyroidism. There was anaemia (Hb 9 g./100 ml., P.C.V. $27 \%$, M.C.H.C. $33.3 \%$ ). $X$-ray examination of the abdomen showed distension of stomach, small intestine, and colon with fluid levels. Barium enema showed gross megacolon; five times the normal quantity of barium was required. The right side of the colon could not be filled, being distended by faeces, but the left half emptied well. The serum cholesterol was $280 \mathrm{mg} . / 100 \mathrm{ml}$. and serum carotene $60 \mu \mathrm{g} . / 100 \mathrm{ml}$. Thyroid function tests showed P.B.I. $2 \cdot 6 \mu \mathrm{g} . / 100 \mathrm{ml}$. (normal 3-8 $\mu$ g./100 ml.) ; 24-hour iodine uptake was only $2 \%$ of a $5-\mu \mathrm{Ci}$ tracer dose.

Although the possibility of mechanical obstruction was entertained it had become evident that the megacolon was part of the gastrointestinal atony of "internal myxoedema." $\mathrm{He}$ was treated by gastric aspiration, intravenous fluids, and triiodothyronine $10 \mu \mathrm{g}$. b.d., but he died on 23 February 1967. Bladder retention was present for 24 hours before death.

At necropsy there was slight left ventricular enlargement. The peritoneal cavity contained $750 \mathrm{ml}$. of fluid (protein $3.7 \mathrm{~g} . / 100 \mathrm{ml}$., cholesterol $25 \mathrm{mg} . / 100 \mathrm{ml}$.). The stomach showed a smooth congested mucosa. Both small and large intestines were dilated, oedematous, and necrotic, but there was no mechanical obstruction.
The bladder was not distended. The pituitary and adrenal glands were normal macroscopically and histologically. The thyroid gland weighed only $8 \mathrm{~g}$. Histologically it consisted mainly of fibrous tissue with a few distorted acini. There was only moderate lymphocytic infiltration without follicle formation.

\section{COMMENT}

In 1935 Escamilla, Lisser, and Shepardson described under the term "internal myxoedema" a case showing cardiac, intestinal, and bladder atony, ascites, secondary anaemia, and carotenaemia due to hypothyroidism, although the external features of this were only scanty. Our patient showed atony of the small and large bowel, ascites, macrocytic anaemia, and bladder retention. He was observed intermittently over nine years ; there were at first no external features of myxoedema, and barium studies of small intestine and colon were initially normal. During the subsequent years there was progressive enlargement of the colon and ultimately generalized intestinal atony. Only in this latter phase did the external signs of myxoedema appear. Thus internal myxoedema can present insidiously as unexplained atony of the gastrointestinal tract or bladder, cardiomegaly, ascites, or macrocytic anaemia. Intestinal atony may affect the stomach, small intestine, and colon. It is rare for it to cause intestinal obstruction as in the case of Escamilla et al. (1935) or our own, and has not to our knowledge been previously described as a cause of death.

Combination of gradually developing constipation with bladder retention or incontinence and slowness of ambulation may simulate a neurological disorder.

The term "internal myxoedema" (Escamilla-Lisser syndrome) embraces anaemia of various types. It is usually normocytic; but macrocytic anaemia, unresponsive to vitamin $\mathbf{B}_{12}$ as in the present instance, may be found. Steadily progressing acquired megacolon should raise the suspicion of internal myxodema even with paucity of external signs. Early treatment by thyroid replacement will result in resumption of normal bowel habit and abdominal girth, whereas parenteral thyroid replacement at the time of generalized dilatation and atony of the bowel may not be sufficient to save the patient. The dangers are atonic intestinal obstruction and perforation.

$$
\begin{aligned}
& \text { J. S. ChadHa, M.B., M.R.C.P.ED. } \\
& \text { D. W. ASHBY, M.D., F.R.C.P. } \\
& \text { W. K. CoWAN, M.D., M.R.C.P.ED., M.C.PATH. }
\end{aligned}
$$

Queen Elizabeth Hospital, Gateshead.

\section{REFERENCE}

Escamilla, R. F., Lisser, H., and Shepardson, H. C. (1935). Annals of Intermal Medicine, 9, 297. 